\title{
Mitochondrial rRNA and tRNA and hearing function
}

\author{
Guangqian Xing ${ }^{1}$, Zhibin $\mathrm{Chen}^{1}$, Xin $\mathrm{Cao}^{2}$ \\ ${ }^{I}$ Department of Otolaryngology, the First Affiliated Hospital of Nanjing Medical University, Nanjing 210029, China; ${ }^{2}$ Department \\ of Biotechnology, Nanjing Medical University, Nanjing 210029, China
}

The human ear is a delicate sensory apparatus of hearing for normal communication, and its proper functioning is highly dependent on mitochondrial oxidative phosphorylation. The first mitochondrial point mutation for nonsyndromic and aminoglycoside-induced hearing loss was identified in 1993. Since then a number of inherited mitochondrial mutations have been implicated in hearing loss. Most of the molecular defects responsible for mitochondrial disorder-associated hearing loss are mutations in the $12 \mathrm{~S}$ rRNA gene and tRNA genes. In this review, after a short description of normal hearing mechanisms and mitochondrial genetics, we outline the recent advances that have been made in the identification of deafness-associated mitochondrial mutations, and discuss how mitochondrial dysfunction contributes to hearing loss.

Keywords: mitochondrial DNA, rRNA, tRNA, gene mutation, aminoglycosides, hearing loss

Cell Research (2007) 17:227-239. doi: 10.1038/sj.cr.7310124; published online 2 January 2007

\section{Introduction}

Hearing loss (hearing impairment/deafness) is the most common sensory disorder in human affecting one in 1000 newborns [1], and $10 \%$ of people aged 65 years or older suffer sufficient hearing loss to benefit from hearing amplification $[2,3]$. Hearing loss can be caused by genetic and environmental factors. Single-gene mutations can also lead to hearing loss. It is estimated that more than $50 \%$ of pediatric cases have a genetic etiology with autosomal dominant, autosomal recessive, $\mathrm{X}$-linked, or mitochondrial mode of inheritance $[4,5]$. There are two monogenic forms of hearing loss including syndromic (characterized by hearing loss in combination with other abnormalities) or nonsyndromic (with only hearing loss) ones. Up to now, more than 130 genetic loci have been described for nonsyndromic deafness [6] that accounts for about $60-70 \%$ inherited hearing impairment in human. Although most hereditary hearing loss is due to nuclear gene defects, it has become clear in recent years that mitochondrial genes also play an important role. Mutations in mitochondrial DNA (mtDNA) can cause

Correspondence: Guangqian Xing

Tel: +86-25-86531424; Fax: +86-25-86611637;

E-mail: xing-gq@163.com both syndromic and nonsyndromic hearing loss [5, 7-11]. Causative mtDNA mutations were found in approximately $5 \%$ of patients in both southern Italy and UK populations with postlingual but early-onset nonsyndromic hearing impairment [12]. In another recent report by Hsu et al. [9], deleterious mtDNA point mutations and/or abnormal mtDNA content or multiple deletions were identified in 20 of 31 subjects with definite mitochondrial syndromic hearing loss, and most of the molecular defects responsible for mitochondrial disorder associated with hearing impairment were mutations in tRNA and rRNA genes. These findings suggest that mitochondrial mutations may be a frequent cause of hearing impairment.

This review focuses on normal hearing mechanisms, the basic mitochondrial genetics, and the most common mutations associated with hearing loss in mitochondrial rRNA and tRNA genes. We also briefly discuss the mechanisms by which mtDNA mutations lead to human hearing disorders.

\section{Mechanisms of normal hearing}

The peripheral auditory system is a complicated sensory apparatus of hearing, which is composed of three anatomical sections: the outer, middle, and inner ears (cochlea). Sound waves impinging on the head are captured and 
transmitted by the outer ear to the tympanic membrane. In response to sound waves, the vibrations of the tympanic membrane are amplified by the ossicular chain of the middle ear to generate compression waves (traveling waves) in the fluid-filled cochlea. The waves move the tectorial membrane in the cochlear duct and produce a shearing motion, which bends the stereocilia of the sensory hair cells of Corti's organ [11].

There are two kinds of sensory cells in the cochlea: the inner hair cell and the outer hair cell (Figure 1). The inner hair cells are pure sensory cells that transmit signals to the acoustic nerve and the auditory cortex. The outer hair cells have both sensory and motor elements that contribute to hearing sensitivity and frequency selectivity [13]. Each hair cell is crowned at its apical pole by a hair bundle called stereocilia. The tip of the stereocilia contains the cationic channel [14]. Deflection of the stereocilia induced by traveling waves opens nonspecific ion channels at the tip of the stereocilia, resulting in current flow $\left(\mathrm{K}^{+}\right)$into the sensory cells. The potassium flux arises from the endocochlear potential of about $+80 \mathrm{mV}$ that is added to the negative intracellular potentials of hair cells. This potassium influx results in a change in membrane potential that is proportional to the intensity of the acoustic stimulus. The resulting intracellular depolarization of the hair cells activates the voltage-sensitive calcium channels on the basolateral side of the cells, leading to calcium influx into the hair cells. Consequently, the calcium inflow triggers the release of neurotransmitters into postsynaptic terminals that activate the afferent nerve fibers [13].

Normally, the endolymph in the cochlear duct has a high potassium and low sodium concentration, and is maintained at a high positive resting potential, the endolymphatic potential. The endolymphatic potential is not generated in response to acoustic stimulation, but arises from the stria

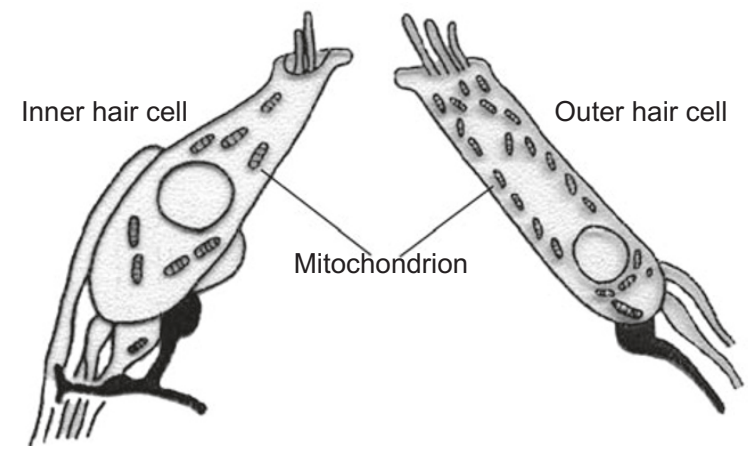

Figure 1 Sensory hair cells of the cochlea. Mitochondria, stereocilia, and synaptic connection between hair cells and primary acoustic neurons are shown. vascularis, a structure on the lateral wall of the cochlear duct responsible for generating the endolymph. The stria vascularis is considered to be the energy source of the cochlea, crucial for the transduction process. The nature of the energy source is related to the heavy vasculature of the stria vascularis and Na-K-ATPase. To maintain a normal endolymphatic potential, it is clearly important that potassium ions accumulated in the hair cells during acoustic stimulation are secreted back into endolymph. Firstly, they pass through potassium channels into the supporting cells. The potassium then passively diffuses through gap junctions from cell to cell until it reaches the stria vascularis. There, it is actively pumped back into the endolymph by Na-K-ATPase pumps, thereby resetting the electrochemical properties and resulting in the efficient energy-yielding process of acoustic transduction [15].

Thus, the proper functioning of the cochlea involves several steps such as membrane depolarization, ion transport, and transmitter release. All these sequences of events must be properly operated for normal hearing. Any malfunction in the genes involved in the cochlear functions can lead to hearing impairments. As we know, cochlear hair cells are abundant with mitochondria (Figure 1), suggesting that hearing is strongly dependent on mitochondrial function.

\section{Mitochondrial genetics}

Mitochondria are found in all nucleated cells as the principal generators of cellular energy, i.e. adenosine 5'-triphosphate (ATP), by oxidative phosphorylation (OXPHOS). Mitochondria are the only location of extrachromosomal DNA within the cell, and they are under the dual genetic control by both nuclear DNA and the mitochondrial genome [10].

There are hundreds of mitochondria in each cell. Each of these mtDNA molecules, which is a double-stranded closed circle, is $16569 \mathrm{bp}$ in length in human, and the total mtDNA comprises only about $1-2 \%$ of the total DNA in mammalian cells. The mitochondrial genome encodes 13 essential polypeptides of OXPHOS as well as two rRNAs and 22 tRNAs, which are required for assembling a functional mitochondrial protein-synthesizing system (Figure 2) [10, 16]. The 13 mRNAs are translated into 13 proteins on mitochondrion-specific ribosomes by using a mitochondrion-specific genetic code. These proteins interact with approximately 60 nuclear encoded proteins to form the five enzyme complexes required for OXPHOS. These complexes are integrated into the mitochondrial inner membrane, and are involved in electron transport and ATP synthesis. Mitochondria are not only essential for the generation of cellular energy but also for the control of apoptosis, and they are the major producers of reactive 


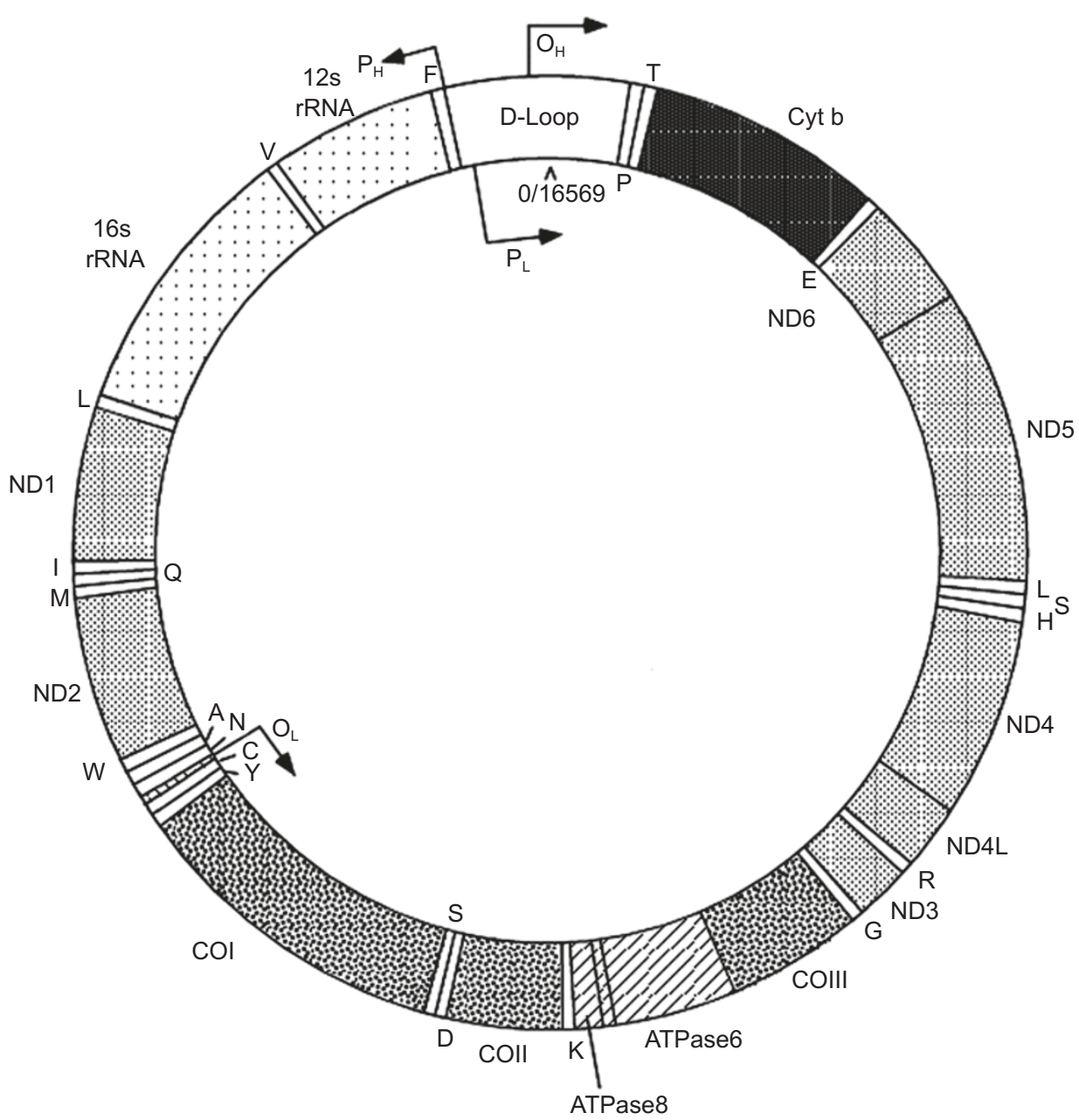

Figure 2 Map of the human mtDNA. The genes that encode the subunits of complex I (ND1-ND6 and ND4L), cytochrome $c$ oxidase (COI-COIII), cytochrome $b$ of complex III, and the subunits of the ATP synthase (ATPase 6 and 8) are shown. The two ribosomal RNAs and 22 tRNAs (white blocks), which are required for mitochondrial protein synthesis are also shown. The displacement loop (D-loop), or noncoding control region, contains sequences that are vital for the initiation of both mtDNA replication and transcription, including the proposed origin of heavy-strand replication (shown as $\mathrm{O}_{\mathrm{H}}$ ). The origin of light-strand replication is shown as $\mathrm{O}_{\mathrm{L}}$. (Cited and modified from 'MITOMAP: A Human Mitochondrial Genome Database. http://www.mitomap.org/, 2006' with written permission).

oxygen species (Figure 3) [13, 17].

Mitochondrial genetics is different from Mendelian genetics in almost every aspect (Table 1) [10]. Owing to maternal inheritance, disease manifestation can only be passed through the matrilineal line. Because mitochondria have a low activity DNA repair system and no histones, and are continuously exposed to oxygen radicals that are leaked from the mitochondrial electron-transfer chain, somatic mutations in mtDNA are common [10]. Normally, most healthy individuals appear to have only a single mtDNA genotype (i.e., are homoplasmic), but, in many mitochon- drial disease states, there are mixed mtDNA genotypes (i.e., heteroplasmic). The amount of heteroplasmy varies from tissue to tissue, and for cells within a tissue. The severity of the symptoms does not always correlate well with the proportion of mutant mitochondrial chromosomes, as different organs rely on mitochondrial OXPHOS to a different extent. The variable clinical phenotypes may be due to organ-specific energetic vulnerability [18]. Phenotypic heterogeneity also exists in the case of homoplasmy, which presumably results from different nuclear genetic backgrounds or mitochondrial haplotypes. Comprehen- 


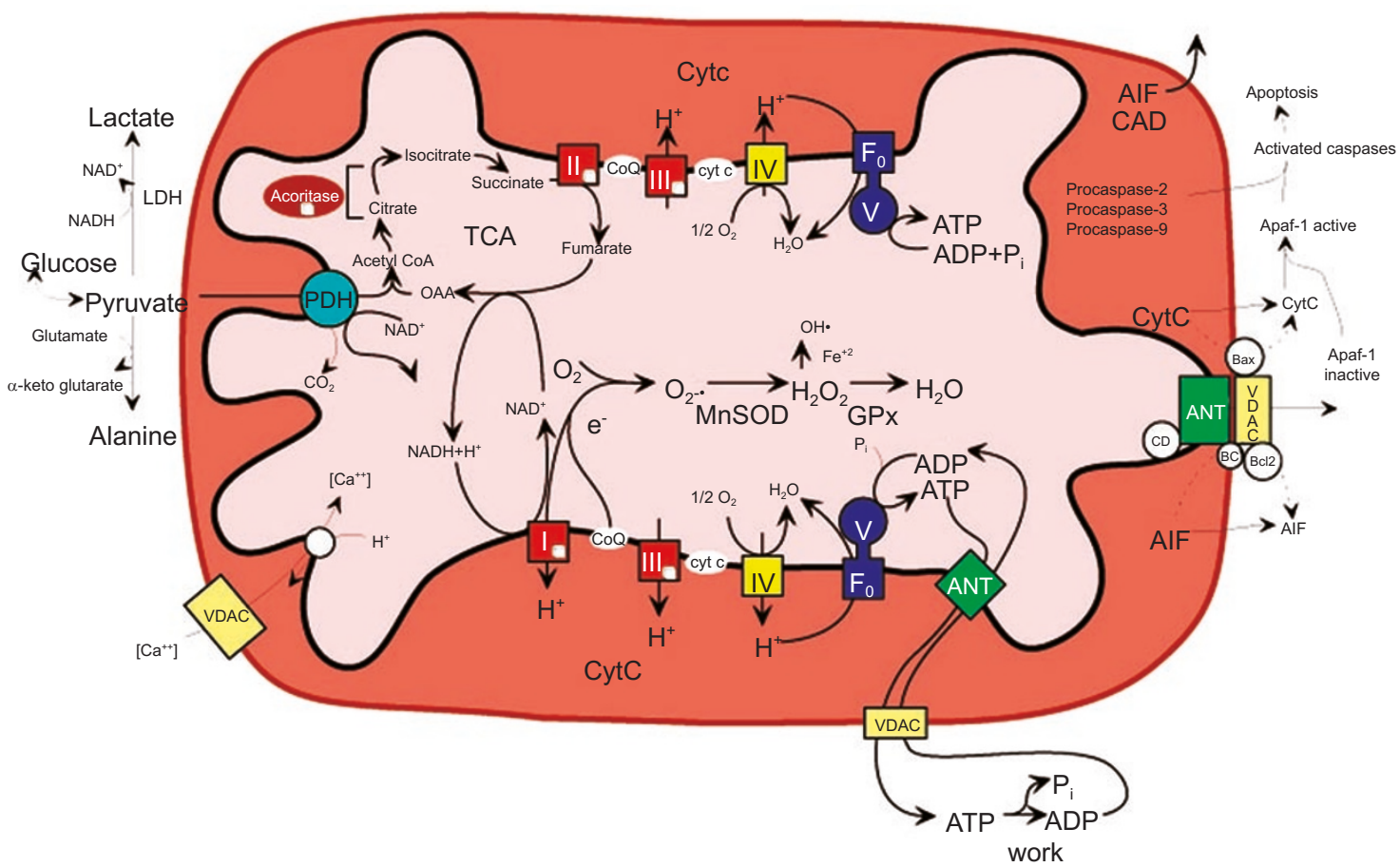

Figure 3 Mitochondrial energetics. Diagram of the mammalian mitochondrion showing the relationship among energy production, reactive oxygen species generation, and regulation of apoptosis (Cited from 'MITOMAP: A Human Mitochondrial Genome Database. http://www.mitomap.org/, 2006' with written permission).

sive reviews of normal mitochondrial genetics have been published (e.g. see [10]).

\section{Mitochondrial defects and hearing loss}

Mitochondrial defects can be inherited or acquired. Inherited mtDNA mutations are responsible for many clinical abnormalities, including various forms of neuropathy, myopathy, cardiomyopathy, retinal degeneration, diabetes mellitus, and sensorineural hearing loss (SNHL) $[5,7,8$, $11,13,19]$. In addition, there is increasing evidence that acquire mtDNA mutations are involved in aging and age-related diseases such as presbycusis [19], cancer, and diabetes [10]. Progressive hearing loss can be one of the symptoms in many patients with classic mitochondrial disorders, such as the myoclonic epilepsy and ragged red fibers (MERRF) [20], Kearns-Sayre syndrome (KSS) [21], and mitochondrial encephalomyopathy with lactic acidosis and stroke-like episodes (MELAS) [22]. Hearing loss can also be the only presentation of mitochondrial defect, suggesting that hearing is strongly dependent on mitochondrial function [5]. Inherited deafness-associated mtDNA mutations usually occur in the genes encoding proteins or genes for components of the protein-synthesizing apparatus, i.e. rRNAs and tRNAs. These data have recently been reviewed $[5,7,8,11,19]$, which are summarized with the inclusion of the most recent data in Table 2 . In this observation, only those mtDNA mutations identified in families and/or suggested by functional studies were selected. Other mtDNA variants, whose relationship with hearing loss has been reported in sporadic individuals while lacking biochemical evidence, were not included even though some could represent rare pathogenic mutations.

\section{Mitochondrial rRNA mutations and nonsyndromic hearing loss}

Mitochondrial rRNA mutations associated with SNHL were only found in the $12 \mathrm{~S}$ rRNA gene. Mutations in this gene cause aminoglycoside-induced and nonsyndromic SNHL, which may be due to the A1555G [23-27], C1494T [28], T1095C [34-37], A827G [40, 41], and 961 mutations [30-33]. No deafness-associated mutations in the mitochondrial 16S rRNA gene have been detected.

The A1555G mutation in the $12 \mathrm{~S}$ rRNA gene was first described in a large Arab-Israeli pedigree [23] and 
Table 1 Comparison between the human nuclear and mitochondrial genomes ${ }^{1}$

\begin{tabular}{|c|c|c|}
\hline Characteristic & Nuclear genome & Mitochondrial genome \\
\hline Size & $\sim 3.3 \times 10^{9} \mathrm{bp}$ & $16569 \mathrm{bp}$ \\
\hline Number of DNA molecules per cell & 23 in haploid cells; 46 in diploid cells & $\begin{array}{l}\text { Several thousand copies per cell } \\
\text { (polyploidy) }\end{array}$ \\
\hline Number of genes encoded & $\sim 20000-30000$ & $\begin{array}{l}37 \text { ( } 13 \text { polypeptides, } 22 \text { tRNAs and } \\
\text { two rRNAs) }\end{array}$ \\
\hline Percentage of coding DNA & $\sim 3 \%$ & $\sim 93 \%$ \\
\hline Codon usage & The universal genetic code & $\begin{array}{l}\text { AUA codes for methionine; TGA } \\
\text { codes for tryptophan; AGA and AGG } \\
\text { specify stop codons }\end{array}$ \\
\hline Mode of inheritance & $\begin{array}{l}\text { Mendelian inheritance for autosomes } \\
\text { and the X chromosome; paternal } \\
\text { inheritance for the } \mathrm{Y} \text { chromosome }\end{array}$ & Exclusively maternal \\
\hline Replication & $\begin{array}{l}\text { Strand-coupled mechanism that uses } \\
\text { DNA polymerases } \alpha \text { and } \delta\end{array}$ & $\begin{array}{l}\text { Strand-coupled and strand- } \\
\text { displacement models; only } \\
\text { uses DNA polymerase } \gamma\end{array}$ \\
\hline Transcription & $\begin{array}{l}\text { Most genes are transcribed } \\
\text { individually }\end{array}$ & $\begin{array}{l}\text { All genes on both strands are } \\
\text { transcribed as large polycistrons }\end{array}$ \\
\hline Recombination & $\begin{array}{l}\text { Each pair of homologues recombines } \\
\text { during the prophase of meiosis }\end{array}$ & $\begin{array}{l}\text { There is evidence that recombination } \\
\text { occurs at a cellular level but little } \\
\text { evidence that it occurs at a } \\
\text { population level }\end{array}$ \\
\hline
\end{tabular}

${ }^{1}$ Table cited from Ref. [10] C (2005) Nature Publishing Group with permission.

${ }^{2}$ TFAM: mitochondrial transcription factor $\mathrm{A}$.

subsequently found in many families of various ethnic backgrounds [24-27, 64-67]. The mutation can be found in $0.6-2.5 \%$ of the Caucasian clinical population with nonsyndromic SNHL [68]. In the Asian nonsyndromic hearing-impaired populations, the incidence of the $\mathrm{A} 1555 \mathrm{G}$ mutation appears to be higher than in Caucasians: $2.9 \%$ in Chinese [39], 3\% in Japanese [69], and 5.3\% in Indonesia [70]. In a recent study, however, it has been reported that as much as $17 \%$ of Spanish population with postlingual nonsyndromic hearing loss assessed in a single Otolaryngology Department carried this mutation [71]; and this is a very high rate of incidence, which is not comparable to other Caucasian populations. Usually, the $\mathrm{A} 1555 \mathrm{G}$ mutation occurs in homoplasmy, but in some families the heteroplasmic state was identified [72]. SNHL for this mutation may be triggered by the use of aminoglycosides, and may also oc- cur without exposure to these drugs [8]. In the absence of aminoglycosides, the $\mathrm{A} 1555 \mathrm{G}$ mutation produces a variable clinical phenotype among family members $[23,26]$. Also, the penetrance differs between families for this mutation. In some pedigrees, most of the individuals carrying the A1555G mutation subsequently develop SNHL [27], but, in others, the penetrance may be extremely low $[73,74]$. These findings indicate that the $\mathrm{A} 1555 \mathrm{G}$ mutation itself is not sufficient to produce a clinical phenotype but requires the involvement of modifier factors for the phenotypic expression. Clinical, genetic, and biochemical data have shown that the aminoglycoside antibiotics [23], mitochondrial haplotypes [33], and nuclear modifier genes [75-77] are three major modulators for the phenotypic expression of the deafness-associated $12 \mathrm{~S}$ rRNA mutations. The A1555G mutation is located at a highly conserved region of $12 \mathrm{~S}$ 
Table 2 Mitochondrial mutations associated with hearing loss

\begin{tabular}{|c|c|c|c|c|}
\hline Gene & Mutations & Manifestation & Aminoglycoside ototoxicity & Reference \\
\hline \multicolumn{5}{|l|}{ 12S rRNA } \\
\hline & A1555G & Nonsyndromic SNHL & + & {$[23-27]$} \\
\hline & C1494T & Nonsyndromic SNHL & + & {$[28,29]$} \\
\hline & $\mathrm{T} 1095 \mathrm{C}$ & $\begin{array}{l}\text { Nonsyndromic SNHL or with } \\
\text { parkinsonism, and neuropathy }\end{array}$ & + & [34-37] \\
\hline & $\mathrm{A} 827 \mathrm{G}$ & Nonsyndromic SNHL & + & {$[38-41]$} \\
\hline \multirow{5}{*}{$\mathrm{tRNA}^{\mathrm{Ser}(\mathrm{UCN})}$} & 7472insC & $\begin{array}{l}\text { Nonsyndromic SNHL or with } \\
\text { neurological dysfunction }\end{array}$ & - & {$[45-47]$} \\
\hline & $\mathrm{T} 7510 \mathrm{C}$ & Nonsyndromic SNHL & - & [48] \\
\hline & $\mathrm{T} 7511 \mathrm{C}$ & Nonsyndromic SNHL & - & [49-53] \\
\hline & $\mathrm{T} 7512 \mathrm{C}$ & $\begin{array}{l}\text { Progressive myoclonic epilepsy, } \\
\text { ataxia and hearing impairment }\end{array}$ & - & {$[54]$} \\
\hline & G7444A & Nonsyndromic SNHL & + & {$[55-57]$} \\
\hline $\mathrm{tRNA}^{\mathrm{Glu}}$ & $\mathrm{T} 14709 \mathrm{C}$ & MIDD & - & {$[61,62]$} \\
\hline Several & Large deletions & KSS & - & [21] \\
\hline Several & $\begin{array}{l}\text { Large } \\
\text { deletion/duplication }\end{array}$ & MIDD & - & {$[63]$} \\
\hline Several & "Random" & Presbycusis & - & [19] \\
\hline
\end{tabular}

${ }^{1}$ MIDD: maternally inherited diabetes and deafness.

rRNA that is an essential part of the decoding site of the small ribosomal subunit and important for the action of aminoglycosides [78]. In human, the nucleotide at position 1555 in the 12S rRNA gene in wild-type cells is A, and, when $A$ is mutated to $G$, it would pair with $C$ at position 1494 $[5,68]$. This transition makes the secondary structure of $12 \mathrm{~S}$ rRNA more closely resemble the corresponding region of
Escherichia coli $16 \mathrm{~S}$ rRNA, which consequently leads to defects in mitochondrial translation and protein synthesis [79]. This new G-C pair is also expected to create a binding site for aminoglycosides, which facilitates interaction with the drugs [80]. Although hearing loss caused by A1555G mutation is usually nonsyndromic, additional symptoms including Parkinson disease and cardiomyopathy have been 
reported on occasions [8].

In studies of a large Chinese family with maternally transmitted aminoglycoside-induced and nonsyndromic hearing loss, Zhao et al. [28] identified a novel C1494T mutation in the mitochondrial $12 \mathrm{~S}$ rRNA gene. In the absence of aminoglycosides, some matrilineal members exhibited late-onset and progressive SNHL, with variable severity and age of onset. Clinical observation showed that the use of aminoglycosides can induce or worsen hearing loss in matrilineal relatives. More recently, Wang et al. [29] reported another Chinese family with aminoglycoside-induced and nonsyndromic hearing loss. Sequence analysis of mtDNA in this pedigree also identified a homoplasmic 12S rRNA C1494T mutation in matrilineal subjects. Zhao et al. [28] suggested that the C1494T mutation would form a new U1494-1555A base pair at the highly conserved aminoacyl-tRNA-binding site (A-site) of the 12S rRNA, which is in the same position as the $\mathrm{C} 1494-1555 \mathrm{G}$ pair created by the $\mathrm{A} 1555 \mathrm{G}$ mutation. In lymphoblastoid cell lines derived from individuals carrying the C1494T mutation, exposure to a high concentration of paromomycin or neomycin caused a variable but significant increase in doubling time, as well as a significant decrease in the rate of total oxygen consumption as compared with controls [28, 81]. These results suggest that the C1494T mutation is a primary factor related to hearing loss and that the nuclear genetic background may play a role in the phenotypic expression associated with this mutation.

The T1095C mutation in the 12S rRNA gene was first identified in an Italian family with deafness, neuropathy, and Parkinsonism [34]. This mutation was also found in another Italian family with maternally inherited hearing loss [35], a Chinese woman with pure auditory neuropathy [36], and four Chinese patients with aminoglycoside-induced and nonsyndromic SNHL $[37,39]$. Thus, the T1095C mutation is expected to cause both syndromic and nonsyndromic hearing loss. This T-to-C transition disrupted an evolutionarily conserved base-pair at stem loop of helix 25 of $12 \mathrm{~S}$ rRNA $[68,82]$, resulting in impaired translation in mitochondrial protein synthesis and a significant reduction of cytochrome $c$ oxidase activity [34], thereby causing the mitochondrial dysfunction associated with hearing loss [68].

Several mutations at position 961 in the 12S rRNA gene have been found in sporadic individuals and genetically unrelated families with aminoglycoside-induced and/or nonsyndromic SNHL. These include ET961C $\mathrm{C}_{\mathrm{n}}$ mutation (The word "ET961C $\mathrm{C}_{\mathrm{n}}$ " means "the deletion of the T nucleotide at position 961 of the mitochondrial 12S rRNA gene, combined with a variable increase in the number of $\mathrm{C}$ nucleotides surrounding position 961 ". This mutation can also be described as "961 delT $+C(n)$ ".) and 961-C insertion in Caucasian and Asian subjects [30-33, 39, 83], T961G mutation in Caucasian patients [38], and T961C mutation in Chinese subjects [39]. The findings clearly indicate that mutation at position 961 is involved in the pathogenesis of hearing impairment $[5,68]$. The 961 mutation localizes at the C-cluster of the region between loop 21 and 22 of $12 \mathrm{~S}$ rRNA [82], which is not very evolutionarily conserved. It is postulated that alteration of the tertiary or quaternary structure of the rRNA caused by the 961 mutation may indirectly affect the binding of aminoglycosides and result in a mitochondrial translation defect $[5,68]$.

More recently, two Chinese pedigrees with maternally inherited nonsyndromic hearing loss have been reported, and a homoplasmic $\mathrm{A} 827 \mathrm{G}$ mutation in the $12 \mathrm{~S}$ rRNA gene in matrilineal relatives has been shown $[40,41]$. Clinical data indicated a strikingly similar phenotype of hearing loss in these families, being moderate to severe, bilateral, and sensorineural with flat configurations. In contrast with the congenital or early-onset hearing impairment in one family carrying the A827G mutation [40], three patients in another pedigree developed hearing loss only after administration of aminoglycosides [41]. The discrepancy likely reflects the difference of genetic backgrounds between two families. This mutation was also previously detected in several sporadic individuals with aminoglycoside-induced and/or nonsyndromic SNHL $[38,39]$. The pathogenicity of the A $827 \mathrm{G}$ mutation is strongly supported by the occurrence of the same mutation in these genetically unrelated subjects. The A827G mutation is located at the A-site of the mitochondrial 12S rRNA gene, which is highly evolutionarily conserved. It is possible that this mutation may lead to mitochondrial dysfunction.

\section{Mitochondrial tRNA mutations associated with non- syndromic hearing loss}

Mitochondrial tRNA genes are one of the hot spots for mutations in maternally inherited SNHL, as a number of deafness-associated mutations have been identified in four of the 22 tRNA genes including the tRNA ${ }^{\text {Ser(UCN) }}$ gene, tRNA $^{\text {Leu(UUR) }}$ gene, tRNA $^{\text {Lys }}$ gene, and tRNA ${ }^{\text {Glu }}$ gene (Table 2) $[5,6,11]$. Usually, mutations in the tRNA ${ }^{\text {Ser(UCN) }}$ gene cause nonsyndromic SNHL, while defects in three other tRNA genes cause only syndromic hearing impairment.

In the mitochondrial tRNA ${ }^{\text {Ser(UCN) }}$ gene, five nonsyndromic deafness-associated mutations, A7445G [42-44], 7472insC [45-47], T7510C [48, 84], T7511C [49-53], and G7444A [55-57], have been found in families from various ethnic backgrounds. These mutations often occur in homoplasmy or in high levels of heteroplasmy, indicating a high threshold for pathogenicity. It is believed that mutations in this gene can cause a failure in tRNA metabolism, thereby 
leading to a decrease in the amount of affected tRNAs, which subsequently results in insufficient mitochondrial protein synthesis and the respiration defects [85].

The A7445G mutation was first described in a family from Scotland [42], and established in two unrelated pedigrees from New Zealand [43] and Japan [44]. In the latter two pedigrees, a mild form of the skin condition palmoplantar keratoderma also segregates in the matrilineal line, and the penetrance of this mutation for hearing loss is much higher than in the Scottish pedigree. This discrepancy seems to be due to a difference in mitochondrial haplotype. In the New Zealand pedigree, three additional sequence changes in complex I protein genes were also detected [43], but similar changes were not found in the Scottish pedigree [86]. The A7445G mutation is a silent change of both the last nucleotide of the $C O I$ gene on the heavy strand and the nucleotide immediately adjacent to the $3^{\prime}$ end of the tRNA $^{\text {Ser(UCN) }}$ gene on the light strand. It is possible that the mutation may affect normal processing of the light-strand polycistronic RNA and lead to significant decreases in the levels of both $\mathrm{tRNA}^{\mathrm{Ser}(\mathrm{UCN})}$ and cotranscripted ND6 mRNA, which subsequently disturbs both mitochondrial protein synthesis and respiration of the mutant cells [85]. A recent study has indicated that the biochemical phenotype associated with the $\mathrm{A} 7445 \mathrm{G}$ mutation was modified by nuclear background [87].

The 7472 ins $C$ mutation in the tRNA ${ }^{\text {Ser(UCN) }}$ gene was described originally in a Sicilian family [45]. Most individuals carrying this mutation had progressive SNHL, and some of them were accompanied by a widespread neurological disease including ataxia, dysarthria, and myoclonic seizures. This mutation was later found in a large Dutch family [46] and in several sporadic subjects with nonsyndromic hearing loss [47]. In the Dutch family, the hearing loss is sensorineural progressive with onset in early adulthood, and only a single family member with hearing loss showed accompanying neurological symptoms. The mutation is heteroplasmic, although most individuals have over $90 \%$ of abnormal mitochondrial chromosomes in the tissues examined [46]. The 7472insC mutation seems to occur multiple times in the European population than others. The mutation alone is usually sufficient to cause hearing loss, and when present at very high levels it can also lead to neurological dysfunction [88]. Biochemical data showed that cell lines carrying this mutation produced a significant decrease in the level of this tRNA, which was combined with a small but clear decrease in the extent of aminoacylation. Only very subtle effects on structure or stability were found $[89,90]$.

In a British family with maternally inherited nonsyndromic hearing loss, a heteroplasmic T-to-C transition at nucleotide 7510 of the tRNA ${ }^{\text {Ser(UCN) }}$ gene was found to be the pathogenic mutation [48]. The same change was also identified in a Spanish pedigree [84]. This mutation is predicted to disrupt base pairing in the acceptor stem of the tRNA, thus causing mitochondrial dysfunction.

The T7511C mutation has been identified to be associated with nonsyndromic SNHL in several families from different ethnic groups, including African [49, 50], French [52], and Japanese [51]. This mutation often exists in homoplasmy in most matrilineal relatives and in a high level of heteroplasmy in some matrilineal relatives. However, the levels of homoplasmy and heteroplasmy did not correlate with the severity and age of onset of hearing loss [49-53]. Despite sharing some common features, matrilineal relatives of intra-families or inter-families carrying the T7511C mutation exhibited variable severity, age of onset, and progression in hearing loss [49-52]. These pedigrees also differ considerably in the penetrance of the T7511C mutation [50-52]. The high variability suggests the existence of genetic and/or environmental factors modifying the phenotypic expression of this mutation. Interestingly, the homoplasmic ND1 T3308C and tRNA ${ }^{\text {Ala }}$ T5655C mutations were found in all maternal members of the African American pedigree [50]. A functional study in cybrid cell lines derived from affected individuals in this family has shown that the T7511C mutation leads to $\sim 75 \%$ decrease in the tRNA ${ }^{\mathrm{Ser}(\mathrm{UCN})}$ level [91]. Furthermore, the T5655C mutation produces $\sim 50 \%$ reduction in the tRNA ${ }^{\text {Ala }}$ level, and the $\mathrm{T} 3308 \mathrm{C}$ mutations causes a significant decrease both in the amount of ND1 mRNA and co-transcribed tRNA $^{\text {Leu(UUR) }}$ [91]. It is reasonable that a combination of the T7511C mutation with two other mtDNA variants may lead to significant biochemical defects in mutant cell lines, and may probably account for the high penetrance of hearing loss in this African American family.

The fifth nonsyndromic deafness-associated mutation in the mitochondrial COI/tRNA ${ }^{\mathrm{Ser}(\mathrm{UCN})}$ gene is the G7444A substitution, which was first identified to coexist with the A1555G mutation in six Mongolian subjects and a Chinese pedigree with aminoglycoside-induced SNHL [55, 56]. This mutation was implicated to be associated with nonsyndromic SNHL [55] or to influence the phenotypic expression of hearing loss associated with the A1555G mutation [56]. The pathogenicity was supported by a recent observation of two Chinese families with aminoglycosideinduced and nonsyndromic SNHL, in which the homoplasmic G7444A mutation was present only in the maternal lineage but not in other members of these pedigrees and 164 Chinese controls [57]. The G7444A mutation is adjacent to the $3^{\prime}$ end endonucleolytic processing site of the L-strand RNA precursor, spanning tRNA ${ }^{\mathrm{Ser}(\mathrm{UCN})}$, and ND6 mRNA. Thus, the G7444A mutation, similar to the A7445G mutation, may also cause a defect in the processing of the L- 
strand RNA precursor and potentially lead to mitochondrial dysfunctions [57]. However, a functional analysis seems necessary to confirm the speculation and to determine if this mutation is sensitive to aminoglycosides.

\section{Mitochondrial tRNA mutations associated with syn- dromic hearing loss}

Unlike mutations in the tRNA ${ }^{\text {Ser(UCN) }}$ gene that usually cause nonsyndromic SNHL, mutations in three other mitochondrial tRNA genes including tRNA ${ }^{\mathrm{Leu}(\mathrm{UUR})}$ gene, tRNA $^{\text {Lys }}$ gene, and tRNA ${ }^{\text {Glu }}$ gene have been associated only with syndromic hearing impairment (Table 2) $[5,6,11]$. The most common forms of mitochondrial syndromic hearing loss are acquired mitochondrial neuromuscular syndromes such as KSS, MERRF, MELAS, as well as maternally inherited diabetes mellitus and deafness (MIDD). Because of the higher energy requirement of nervous tissue, it is not unexpected that generalized neuronal dysfunction caused by mutation in patients with mitochondrial disorders may also express in the auditory system [19].

In 1992, several families with MIDD were described and found to harbor the identical A3243G mutation in heteroplasmy in the tRNA ${ }^{\text {Leu(UUR) }}$ gene $[58,92]$, which interestingly was also identified in subjects with systematic MELAS syndrome [8, 22, 93]. Furthermore, the heteroplasmic point mutations $\mathrm{T} 14709 \mathrm{C}$ in the tRNA ${ }^{\mathrm{Glu}}$ gene $[61,62]$ and $A 8296 \mathrm{G}$ in the tRNA ${ }^{\text {Lys }}$ gene $[60]$ were also found to be associated with MIDD. In these patients, the hearing loss is sensorineural and it develops usually after the onset of diabetes. Other heteroplasmic mtDNA mutations implicated to be associated with maternally inherited syndromic hearing loss are C3256T in the tRNA ${ }^{\mathrm{Leu}(\mathrm{UUR})}$ gene, A8344G, and T8356C in the tRNA ${ }^{\text {Lys }}$ gene $[11,18$, 59]. These three mutations account for MERRF, a disease characterized by myoclonus, epilepsy, and ataxia, in which the degree of hearing loss is variable.

The only pathogenic mutation identified in the tRNA $^{\text {Ser(UCN) }}$ gene causing syndromic SNHL is a T-to-C transition at position 7512 . The patients carrying this mutation develop SNHL, ataxia, myoclonic epilepsy, and mental retardation [54]. Similar to the T7510C mutation, the $\mathrm{T} 7512 \mathrm{C}$ mutation disrupts a highly conserved base pair in the acceptor stem of the tRNA.

\section{mtDNA mutations and aminoglycoside ototoxicity}

Aminoglycoside antibiotics, such as gentamycin, streptomycin, kanamycin, and tobramycin, are drugs widely used for controlling bacteria-related infections, especially in developing countries. They are known to exert antibacterial effects by directly binding to the $16 \mathrm{~S}$ rRNA of the bacte- rial ribosome, causing insufficient protein synthesis [94]. It is evidenced that the A-site of the small ribosomal RNA is the primary target site for aminoglycoside antibiotics [95]. However, when administrated with high doses or for a long period, these drugs may become concentrated in fluids of the cochlea and potentially lead to ototoxicity [96]. Clinically, some patients developed hearing loss after treatment with only conventional doses, or even with a single dose of drug or over a short period. These cases of aminoglycoside ototoxicity may have a genetic predisposition with various patterns of inheritance [68]. Interestingly, in familial cases of ototoxic deafness, the aminoglycoside hypersensitivity is predominantly transmitted through maternal inheritance, suggesting mitochondrial genome involvement [19]. As the human mitochondrial ribosomes share many similarities to bacterial ribosomes, it is proposed that one of the primary targets for the aminoglycoside antibiotics in human cells is 12S rRNA of mitochondrial ribosome [5].

By now, several mutations including A1555G [23-27], C1494T [28], T1095C [34-37], A827G [40, 41], and 961 mutation [30-33] in the mitochondrial 12S rRNA gene have been found to be associated with nonsyndromic hearing loss. Surprisingly, all of these mutations are sensitive to aminoglycosides as indicated by extensive clinical observations and functional studies [5, 41, 68]. The A1555G mutation seems to be the most common cause of aminoglycoside-induced hearing loss, especially in those cases with a family history $[7,96]$. This mutation accounts for $33 \%$ of a Japanese outpatient population with a history of exposure to aminoglycosides [69], while $13 \%$ of the Chinese pediatric subjects with aminoglycoside ototoxicity carry the A1555G mutation [39]. In two Caucasian populations, $17 \%$ and $17.7 \%$ of cases in US and Spanish cohorts with aminoglycoside ototoxicity harbor this mutation, respectively $[26,97]$. All of these indicate that the mitochondrial genome, especially the $12 \mathrm{~S}$ rRNA gene, is a hot mutation spot for nonsyndromic SNHL as well as aminoglycoside ototoxicity.

Based on the genetic and biochemical evidence, Guan [5] has hypothesized the following mechanism for aminoglycoside susceptibility. The drugs accumulate in the mitochondria of the inner ear after administration, where they inhibit mitochondrial protein synthesis by interacting with the 12S rRNA, which in turn causes a decrease in ATP production in the cochlear hair cells. At the same time, the defects in OXPHOS lead to increased generation of reactive oxygen species, thereby damaging mitochondrial and cellular proteins, lipids, and nucleic acids. Consequently, the mitochondrial permeability transition pore opens, leading to activation of apoptosis. This results in cochlear dysfunction or cell death and gives rise to hearing loss.

Mutations in mitochondrial $12 \mathrm{~S}$ rRNA represent a mo- 
lecular basis for aminoglycoside ototoxicity in a significant portion but do not account for all the cases [68], it is thus anticipated that additional mutations causing drug susceptibility can be found in the mitochondrial genome. Recently, the G7444A mutation in the tRNA ${ }^{\text {Ser(UCN) }}$ gene has been described in two Chinese families with aminoglycosideinduced hearing loss [57]; however, its pathogenicity has not been established.

\section{The mechanisms by which mitochondrial dysfunction causes hearing loss}

Extensive audiological and clinical observations of subjects with mitochondrial diseases suggested a cochlear dysfunction owing to outer hair cell damages $[27,71,98]$ and the presence of intact acoustic nerve [99]. Histological studies of the inner ear from mitochondrial deafness patients and experimental animals showed advanced cochlear degeneration including organ of Corti, stria vascularis, and supporting cells $[7,100]$. Similar pathological changes were not observed in the vestibule, semicircular canal, or among the vestibular nerve fibers [100].

Thus, the cells most likely involved by a mitochondrial defect are the sensory hair cells and those of the stria vascularis in the cochlea. However, it is still unclear how mtDNA mutations induce hearing loss. Deficiencies in mitochondrial OXPHOS appear to be the main pathogenic factors, although the reactive oxygen species generation and altered apoptotic signaling may also play a role [101]. One possibility could be the heavy dependence of the energy metabolism of the organ of Corti and the stria vascularis on mitochondrial OXPHOS [102]. The progressive accumulation of the mutant mtDNA with age causes a decline in the OXPHOS capacity. Energy-dependent ATPase and the release of neurotransmitters in the cochlea are then suppressed by reduced ATP production [102]. Another possibility is a disturbance in ion transport, leading to a reduction in the efficiency of acoustic transduction [7, 102]. As we know, the stria vascularis is the most metabolically active site in the cochlea, and its primary function is to maintain the ionic environment of hair cells [103]. This requires ATP-dependent pumps to secrete potassium ions back into the endolymph against an ionic gradient. The declined production of ATP owing to mitochondrial dysfunction may slow down these pumps, which in turn leads to an imbalance of ionic environment in the inner ear, and a pronounced reduction of the capacity for the cochlea to detect and transmit sound waves [7]. Also, the reduced ATP production would activate both nonselective cation channels and $\mathrm{I}_{\mathrm{SK}}$ channels in the strial marginal cells and inactivate the $\mathrm{Ca}^{2+}$-ATPase in the outer hair cells [102].

\section{Summary}

The human ear is a complicated sensory organ that has specialized hair cells to detect mechanical stimuli of sound and convert them into afferent nerve signals. These sensory cells are also extremely fragile to a number of intrinsic and extrinsic factors that are responsible for hearing loss. The maintenance of normal hearing mechanism is highly dependent on the ATP produced by mitochondrial oxidative phosphorylation.

Over the past decades, mitochondrial defects have been implicated in many degenerative diseases as well as hearing impairment. Inherited deafness-associated mtDNA mutations usually occur in the genes encoding proteins or genes for components of the protein-synthesizing apparatus, i.e. rRNAs and tRNAs. Up to now, five point mutations in the mitochondrial 12S rRNA gene have been found to be associated with nonsyndromic SNHL, and these mutations also account for most of the cases of aminoglycoside ototoxicity. Another hot spot for mutations associated with hearing loss is tRNA ${ }^{\text {Ser(UCN) }}$ gene, as six deafness-associated mutations have been identified in this gene. In addition, the defects in three other tRNA genes including tRNA ${ }^{\text {Leu(UUR) }}$ gene, tRNA ${ }^{\text {Lys }}$ gene, and tRNA ${ }^{\text {Glu }}$ gene have been found only with syndromic SNHL. Usually, a single mutation in the mitochondrial rRNA gene or tRNA gene is not sufficient to cause hearing loss, but requires the contribution of other modulating factors such as nuclear modifier gene(s), environment factor(s), or mitochondrial haplotypes for the phenotypic expression.

How mitochondrial dysfunction contributes to the pathogenesis of hearing loss is still unclear. The essential role of mitochondrial OXPHOS in cellular energy production, the generation of reactive oxygen species, and the initiation of apoptosis may suggest a number of novel mechanisms for mitochondrial deafness.

\section{Acknowledgments}

We acknowledge the support by a grant award from Jiangsu Natural Science Foundation, Grant No. BK2006247; and grant awards from Jiangsu Health Administration, Grant No. WK0623 and K200502.

\section{References}

1 Morton NE. Genetic epidemiology of hearing impairment. Ann NY Acad Sci 1991; 630:16-31.

2 Steel KP. New interventions in hearing impairment. BMJ 2000; 320:622-625.

3 Hone SW, Smith RJH. Genetic screening for hearing loss. Clin Otolaryngol 2003; 28:285-290.

4 Morton CC. Genetics, genomics and gene discovery in the audi- 
tory system. Hum Mol Genet 2002; 11:1229-1240.

5 Guan MX. Molecular pathogenetic mechanism of maternally inherited deafness. Ann NY Acad Sci 2004; 1011:259-271.

6 Van Camp G, Smith RJH. Hereditary Hearing Loss Homepage. URL: http://webhost.ua.ac.be/hhh/. Last updated: 2006, Jul.

7 Hutchin TP, Cortopassi GA. Mitochondrial defects and hearing loss. Cell Mol Life Sci 2000; 57:1927-1937.

8 Van Camp G, Smith RJH. Maternally inherited hearing impairment. Clin Genet 2000; 57:409-414.

9 Hsu CH, Kwon H, Perng CL, Bai RK, Dai P, Wong LJC. Hearing loss in mitochondrial disorders. Ann NY Acad Sci 2005; 1042:36-47.

10 Taylor RW, Turnbull DM. Mitochondrial DNA mutations in human disease. Nat Rev Genet 2005; 6:389-402.

11 Finsterer J, Fellinger J. Nuclear and mitochondrial genes mutated in nonsyndromic impaired hearing. Int J Pediatr Otorhinolaryngol 2005; 69:621-647.

12 Jacobs HT, Hutchin TP, Käppi T, et al. Mitochondrial DNA mutations with postlingual, nonsyndromic hearing impairment. Eur J Hum Genet 2005; 13:26-33.

13 Epstein FH. Genetic causes of hearing loss. N Eng J Med 2000; 342:1101-1109.

14 Denk W, Holt JR, Shepherd GMG, Corey DP. Calcium imaging of single stereocilia in hair cells: Localization of transduction channels at both ends of tip links. Neuron 1995; 15:1311-1321.

15 Tekin M, Arnos KS, Pandya S. Advance in hereditary deafness. Lancet 2001; 358:1082-1090.

16 Anderson S, Bankier AT, Barrell BG, et al. Sequence and organization of the human mitochondrial genome. Nature 1981; 290:457-465.

17 Wallace DC. Mitochondrial diseases in man and mouse. Science 1999; 283:1482-1488.

18 Shoffner JM, Wallace DC. Oxidative phosphorylation diseases. Disorders of two genomes. Adv Hum Genet 1990; 19:267-330.

19 Fischel-Ghodsian N. Mitochondrial deafness mutations reviewed. Hum Mutat 1999; 13:261-270.

20 Shoffner JM, Lott MT, Lezza AM, Seibel P, Ballinger SW, Wallace DC. Myoclonic epilepsy and ragged-red fiber disease (MERRF) is associated with a mitochondrial DNA tRNA ${ }^{\text {Lys }}$ mutation. Cell 1990; 61:931-937.

21 Zeviani M, Moraes CT, DiMauro S, et al. Deletions of mitochondrial DNA in Kearns-Sayre syndrome. Neurology 1988; 38:1339-1346.

22 Goto Y, Nonaka I, Horai S. A mutation in the tRNA ${ }^{\text {Leu(UUR) }}$ gene associated with the MELAS subgroup of mitochondrial encephalomyopathies. Nature 1990; 348:651-653.

23 Prezant TR, Agapian JV, Bohlman MC, et al. Mitochondrial ribosomal RNA mutation associated with both antibiotic-induced and non-syndromic deafness. Nat Genet 1993; 4:289-294.

24 Matthijs G, Claes S, Longo-Mbenza B, Cassiman JJ. Nonsyndromic deafness associated with a mutation and a polymorphism in the mitochondrial $12 \mathrm{~S}$ ribosomal RNA gene in a large Zairian pedigree. Eur J Hum Genet 1996; 4:46-51.

25 Pandya A, Xia X, Radnaabazar J, et al. Mutation in the mitochondrial $12 \mathrm{~S}$ ribosomal-RNA gene in two families from Mongolia with matrilineal aminoglycoside ototoxicity. J Med Genet 1997; 34:169-172.

26 Estivill X, Govea N, Barcelo' A, et al. Familial progressive sensorineural deafness is mainly due to the mtDNA A1555G mutation and is enhanced by treatment with aminoglycosides. Am J Hum Genet 1998; 62:27-35.

$27 \mathrm{Bu}$ X, Xing G, Yan M. Audiological and molecular findings in a large family with maternally inherited sensorineural hearing loss. J Audiol Med 2000; 9:61-69.

28 Zhao H, Li R, Wang Q, et al. Maternally inherited aminoglycoside-induced and nonsyndromic deafness is associated with the novel C1494T mutation in the mitochondrial 12S rRNA gene in a large Chinese family. Am J Hum Genet 2004; 74:139-152.

29 Wang Q, Li QZ, Han D, et al. Clinical and molecular analysis of a four-generation Chinese family with aminoglycoside-induced and nonsyndromic hearing loss associated with the mitochondrial 12S rRNA C1494T mutation. Biochem Biophys Res Commun 2006; 340:583-588.

30 Bacino C, Prezant TR, Bu X, Fournier P, Fischel-Ghodsian N. Susceptibility mutations in the mitochondrial small ribosomal RNA gene in aminoglycoside induced deafness. Pharmacogenetics $1995 ; \mathbf{5}: 165-172$.

31 Casano RA, Johnson DF, Bykhovskaya Y, Torricelli F, Bigozzi M, Fischel-Ghodsian N. Inherited susceptibility to aminoglycoside ototoxicity: genetic heterogeneity and clinical implications. Am J Otolaryngol 1999; 20:151-156.

32 Tang HY, Hutcheson E, Neill S, Drummond-Borg M, Speer M, Alford RL. Genetic susceptibility to aminoglycoside ototoxicity: How many are at risk? Genet Med 2002; 4:336-345.

33 Li R, Xing G, Yan M, et al. Cosegregation of C-insertion at position 961 with A1555G mutation of mitochondrial 12S rRNA gene in a large Chinese family with maternally inherited hearing loss. Am J Med Genet 2004; 124A:113-117.

34 Thyagarajan D, Bressman S, Bruno C, et al. A novel mitochondrial $12 \mathrm{~S}$ rRNA point mutation in parkinsonism, deafness, and neuropathy. Ann Neurol 2000; 48:730-736.

35 Tessa A, Giannotti A, Tieri L, Vilarinho L, Marotta G, Santorelli FM. Maternally inherited deafness associated with a T1095C mutation in the mtDNA. Eur J Hum Genet 2001; 9:147-149.

36 Wang Q, Li R, Zhao H, et al. Clinical and molecular characterization of a Chinese patient with auditory neuropathy associated with mitochondrial 12S rRNA T1095C mutation. Am J Med Genet 2004; 133A:27-30.

37 Zhao L, Young WY, Li R, Wang Q, Qian Y, Guan MX. Clinical evaluation and sequence analysis of the complete mitochondrial genome of three Chinese patients with hearing impairment associated with the 12S rRNA T1095C mutation. Biochem Biophys Res Commun 2004; 325:1503-1508.

38 Li R, Greinwald JH, Yang L, Choo DI, Wenstrup RJ, Guan MX. Molecular analysis of mitochondrial $12 \mathrm{~S}$ rRNA and tRNA ${ }^{\mathrm{Ser}(\mathrm{UCN})}$ genes in pediatric subjects with nonsyndromic hearing loss. J Med Genet 2004; 41:615-620.

$39 \mathrm{Li} \mathrm{Z,} \mathrm{Li} \mathrm{R,} \mathrm{Chen} \mathrm{J,} \mathrm{et} \mathrm{al.} \mathrm{Mutational} \mathrm{analysis} \mathrm{of} \mathrm{the} \mathrm{mitochondrial}$ 12S rRNA gene in Chinese pediatric subjects with aminoglycoside-induced and nonsyndromic hearing loss. Hum Genet 2005; 117:9-15.

40 Xing G, Chen Z, Wei Q, et al. Maternally inherited non-syndromic hearing loss associated with mitochondrial $12 \mathrm{~S}$ rRNA A $827 \mathrm{G}$ mutation in a Chinese family. Biochem Biophys Res Commun 2006; 344:1253-1257.

41 Xing G, Chen Z, Wei Q, et al. Mitochondrial 12S rRNA A827G mutation is involved in the genetic susceptibility to aminoglycoside ototoxicity. Biochem Biophys Res Commun 2006; 
346:1131-1135

42 Reid FM, Vernham GA, Jacobs HT. A novel mitochondrial point mutation in a maternal pedigree with sensorineural deafness. Hum Mutat 1994; 3:243-247.

43 Fischel-Ghodsian N, Prezant TR, Fournier P, Stewart IA, Maw M. Mitochondrial tRNA mutation associated with nonsyndromic deafness. Am J Otolaryngol 1995; 16:403-408.

44 Sevior KB, Hatamochi A, Stewart IA, et al. Mitochondrial A7445G mutation in two pedigrees with palmoplantar keratoderma and deafness. Am J Med Genet 1998; 75:179-185.

45 Tiranti V, Chariot P, Carella F, et al. Maternally inherited hearing loss, ataxia and myoclonus associated with a novel point mutation in mitochondrial tRNA ${ }^{\mathrm{Ser}(\mathrm{UCN})}$ gene. Hum Mol Genet 1995; 4:1421-1427.

46 Verhoeven K, Ensink RJH, Tiranti V, et al. Hearing impairment and neurological dysfunction associated with a mutation in the mitochondrial tRNA ${ }^{\text {Ser(UCN) }}$ gene. Eur J Hum Genet 1999; 7:4551.

47 Jacobs HT, Hutchin TP, Käppi T, et al. Mitochondrial DNA mutations in patients with postlingual, nonsyndromic hearing impairment. Eur J Hum Genet 2005; 13:26-33.

48 Hutchin TP, Parker MJ, Young ID, et al. A novel mutation in the mitochondrial tRNA ${ }^{\mathrm{Ser}(\mathrm{UCN})}$ gene in a family with nonsyndromic sensorineural hearing impairment. J Med Genet 2000; 37:692694.

49 Friedman RA, Bykhovskaya Y, Sue CM, et al. Maternally inherited nonsyndromic hearing loss. Am J Med Genet 1999; 84:369-372.

50 Sue CM, Tanji K, Hadjigeorgiou G, et al. Maternally inherited hearing loss in a large kindred with a novel T7511C mutation in the mitochondrial DNA tRNA ${ }^{\text {Ser(UCN) }}$ gene. Neurology 1999; 52:1905-1908.

51 Ishikawa K, Tamagawa Y, Takahashi K, et al. Nonsyndromic hearing loss caused by a mitochondrial T7511C mutation. Laryngoscope 2002; 112:1494-1499.

52 Chapiro E, Feldmann D, Denoyelle F, et al. Two large French pedigrees with nonsyndromic sensorineural deafness and the mitochondrial DNA T7511C mutation: evidence for a modulatory factor. Eur J Hum Genet 2002; 10:851-856.

$53 \mathrm{Li} \mathrm{R}$, Ishikawa K, Deng JH, et al. Maternally inherited nonsyndromic hearing loss is associated with the T7511C mutation in the mitochondrial tRNA ${ }^{\mathrm{Ser}(\mathrm{UCN})}$ gene in a Japanese family. Biochem Biophys Res Commun 2005; 328:32-37.

54 Jaksch M, Klopstock T, Kurlemann G, et al. Progressive myoclonus epilepsy and mitochondrial myopathy associated with mutations in the tRNA ${ }^{\text {Ser(UCN)) }}$ gene. Ann Neurol 1998; 44:635640.

55 Pandya A, Xia XJ, Erdenetungalag R, et al. Heterogenous point mutations in the mitochondrial tRNA ${ }^{\operatorname{Ser}(\mathrm{UCN})}$ precursor coexisting with the A1555G mutation in deafness students from Mongolia. Am J Hum Genet 1999; 65:1803-1806.

56 Yuan H, Qian Y, Xu Y, et al. Cosegregation of the G7444A mutation in the mitochondrial COI/tRNA ${ }^{\text {Ser(UCN) }}$ genes with the 12S rRNA A1555G mutation in a Chinese family with aminoglycoside-induced and nonsyndromic hearing loss. Am J Med Genet 2005; 138A:133-140.

57 Zhu Y, Qian Y, Tang X, et al. Aminoglycoside-induced and nonsyndromic hearing loss is associated with the G7444A mutation in the mitochondrial COI/tRNA ${ }^{\mathrm{Ser}(\mathrm{UCN})}$ genes in two Chinese families. Biochem Biophys Res Commun 2006; 342:843-850.

58 Van den Ouweland JM, Lemkes HHP, Ruitenbeek W, et al. Mutation in mitochondrial tRNA ${ }^{\text {Leu(UUR) }}$ gene in a large pedigree with maternally transmitted type II diabetes mellitus and deafness. Nat Genet 1992; 1:368-371.

59 Zeviani M, Muntoni F, Savarese N, et al. A MERRF/MELAS overlap syndrome associated with a new point mutation in the mitochondrial DNA tRNA ${ }^{\text {Lys }}$ gene. Eur J Hum Genet 1993; 1:8087.

60 Kameoka K, Isotani H, Tanaka K, et al. Novel mitochondrial DNA mutation in tRNA(Lys) $(8296 \mathrm{~A} \rightarrow \mathrm{G})$ associated with diabetes. Biochem Biophys Res Commun 1998; 245:523-527.

61 Hao H, Bonilla E, Manfredi G, DiMauro S, Moraes CT. Segregation patterns of a novel mutation in the mitochondrial tRNA glutamic acid gene associated with myopathy and diabetes mellitus. Am J Hum Genet 1995; 56:1017-1025.

62 Rigoli L, Prisco F, Caruso RA, et al. Association of the T14709C mutation of mitochondrial DNA with maternally inherited diabetes mellitus and/or deafness in an Italian family. Diabetic Med 2001; 18:334-336.

63 Ballinger SW, Shoffner JM, Hedaya EV, et al. Maternally transmitted diabetes and deafness associated with a $10.4 \mathrm{~kb}$ mitochondrial DNA deletion. Nat Genet 1992; 1:11-15.

64 Mkaouar-Rebai E, Tlili A, Masmoudi S, et al. Mutational analysis of the mitochondrial 12S rRNA and tRNA ${ }^{\text {Ser(UCN) }}$ genes in Tunisian patients with nonsyndromic hearing loss. Biochem Biophys Res Commun 2006; 340:1251-1258.

65 Casino RA, Bykhovskaya Y, Johnson DF, et al. Hearing loss due to the mitochondrial A1555G mutation in Italian families. Am J Med Genet 1998; 79:388-391.

66 Abe S, Usami S, Shinkawa H, et al. Phylogenetic analysis of mitochondrial DNA in Japanese pedigrees of sensorineural hearing loss associated with the A1555G mutation. Eur J Hum Genet 1998; 6:563-569.

67 Malik S, Sudoyo H, Sasmono T, et al. Nonsyndromic sensorineural deafness associated with the $\mathrm{A} 1555 \mathrm{G}$ mutation in the mitochondrial small subunit ribosomal RNA in a Balinese family. J Hum Genet 2003; 48:119-124.

68 Guan MX. Prevalence of mitochondrial 12S rRNA mutations associated with aminoglycoside ototoxicity. Volta Rev 2005; 105:211-227.

69 Usami S, Abe S, Akita J, et al. Prevalence of mitochondrial gene mutations among hearing impaired patients. J Med Genet 2000; 37:38-40.

70 Malik SG, Pieter N, Sudoyo H, Kadir A, Marzuki S. Prevalence of the mitochondrial DNA A1555G mutation in sensorineural deafness patients in island Southeast Asia. J Hum Genet 2003; 48:480-483.

71 Bravo O, Ballana E, Estivill X. Cochlear alterations in deaf and unaffected subjects carrying the deafness-associated A1555G mutation in the mitochondrial 12S rRNA gene. Biochem Biophys Res Commun 2006; 344:511-516.

72 del Castillo FJ, Rodriguez-Ballesteros M, Martin Y, et al. Heteroplasmy for the $1555 \mathrm{~A}-\mathrm{G}$ mutation in the mitochondrial $12 \mathrm{~S}$ rRNA gene in six Spanish families with nonsyndromic hearing loss. J Med Genet 2003; 40:632-636.

73 Young WY, Zhao L, Qian Y, et al. Extremely low penetrance of hearing loss in four Chinese families with the mitochondrial $12 \mathrm{~S}$ rRNAA1555G mutation. Biochem Biophys Res Commun 2005; 
328:1244-1251.

74 Dai P, Liu X, Han D, et al. Extremely low penetrance of deafness associated with the mitochondrial $12 \mathrm{~S}$ rRNA mutation in 16 Chinese families: implication for early detection and prevention of deafness. Biochem Biophys Res Commun 2006; 340:194-199.

75 Guan MX, Fischel-Ghodsian N, Attardi G. Nuclear background determines biochemical phenotype in the deafness-associated mitochondrial 12S rRNA mutation. Hum Mol Genet 2001; 10:573-580.

76 Abe S, Kelley PM, Kimberling WJ, Usami SI. Connexin 26 gene (GJB2) mutation modulates the severity of hearing loss associated with the $1555 \mathrm{~A} \rightarrow \mathrm{G}$ mitochondrial mutation. Am J Med Genet 2001; 103:334-338.

77 Yan Q, Bykhovskaya Y, Li R, et al. Human TRMU encoding the mitochondrial 5-methylaminomethyl-2-thiouridylate-methyltransferase is a putative nuclear modifier gene for the phenotypic expression of the deafness-associated 12S rRNA mutations. Biochem Biophys Res Commun 2006; 342:1130-1136.

78 Fourmy D, Recht MI, Blanchard SC, Puglisi JD. Structure of the A-site of Escherichia coli 16S ribosomal RNA complexed with an aminoglycoside antibiotic. Science 1996; 274:1367-1371.

79 Guan MX, Fischel-Ghodsian N, Attardi G. A biochemical basis for the inherited susceptibility to aminoglycoside ototoxicity. Hum Mol Genet 2000; 9:1787-1793.

80 Hamasaki K, Rando RR. Specific binding of aminoglycosides to a human rRNA construct based on a DNA polymorphism, which causes aminoglycoside-induced deafness. Biochemistry 1997; 36:12323-12328.

81 Zhao H, Young WY, Yan Q, et al. Functional characterization of the mitochondrial 12S rRNA C1494T mutation associated with aminoglycoside-induced and non-syndromic hearing loss. Nucleic Acids Res 2005; 33:1132-1139.

82 Neefs JM, Van de Peer Y, De Rijik P, Goris A, De Wachter R. Compilation of small ribosomal subunit RNA sequence. Nucleic Acids Res 1991; 19 (Suppl):1987-2018.

83 Yoshida M, Shintani T, Hirao M, Himi T, Yamaguchi A, Kikuchi K. Aminoglycoside-induced hearing loss in a patient with the 961 mutation in mitochondrial DNA. ORL J Oto-Rhino-Laryngol Relat Spec 2002; 64:219-222.

84 del Castillo FJ, Villamar M, Moreno-Pelayo MA, et al. Maternally inherited nonsyndromic hearing impairment in a Spanish family with the $7510 \mathrm{~T} \rightarrow \mathrm{C}$ mutation in the mitochondrial tRNA $^{\text {Ser(UCN) }}$ gene. J Med Genet 2002; 39:e82.

85 Guan MX, Enriquez JA, Fischel-Ghodsian N, et al. The deafness-associated mitochondrial DNA mutation at position 7445 , which affects tRNA ${ }^{\text {Ser(UCN) }}$ precursor processing, has long-range effects on NADH dehydrogenase subunit ND6 gene expression. Mol Cell Biol 1998; 18:5868-5879.

86 Reid FM, Vernham GA, Jacobs HT. Complete mtDNA sequence of a patient in a maternal pedigree with sensorineural deafness. Hum Mol Genet 1994; 3:1435-1436.

87 Li X, Zhang LS, Fischel-Ghodsian N, Guan MX. Biochemical characterization of the deafness-associated mitochondrial
tRNA $^{\text {Ser(UCN) }}$ A7445G mutation in osteosarcoma cell cybrids. Biochem Biophys Res Commun 2005; 328:491-498.

88 Hutchin TP, Navarro-Coy NC, Van Camp G, et al. Multiple origins of the mtDNA 7472insC mutation associated with hearing loss and neurological dysfunction. Eur J Hum Genet 2001; 9:385-387.

89 Toompuu M, Yasukawa T, Suzuki T, et al. The 7472insC mitochondrial DNA mutation impairs the synthesis and extent of aminoacylation of tRNA ${ }^{\mathrm{Ser}(\mathrm{UCN})}$ but not its structure or rate of turnover. J Biol Chem 2002; 277:22240-22250.

90 Toompuu M, Tiranti V, Zeviani M, Jacobs HT. Molecular phenotype of the np 7472 deafness-associated mitochondrial mutation in osteosarcoma cell cybrids. Hum Mol Genet 1999; 8:2275-2283.

91 Li X, Fischel-Ghodsian N, Schwartz F, Yan Q, Friedman RA, Guan MX. Biochemical characterization of the mitochondrial tRNA $^{\text {Ser(UCN) }}$ T7511C mutation associated with nonsyndromic deafness. Nucleic Acids Res 2004; 32:867-877.

92 Reardon W, Ross RJ, Sweeney MG, et al. Diabetes mellitus associated with a pathogenic point mutation in mitochondrial DNA. Lancet 1992; 340:1376-1379.

93 Chae JH, Hwang H, Lim BC, Cheong HI, Hwang YS, Kim KJ. Clinical features of A3243G mitochondrial tRNA mutation. Brain Dev 2004; 26:459-462.

94 Noller HF. Ribosomal RNA and translation. Ann Rev Biochem 1991; 60:191-227.

95 Fourmy D, Recht MI, Puglisi JD. Binding of neomycin-class aminoglycoside antibiotics to A-site of 16S rRNA. J Mol Biol 1998; 277:347-362.

96 Fischel-Ghodsian N. Genetic factors in aminoglycoside toxicity. Pharmacogenomics 2005; 6:27-36.

97 Fischel-Ghodsian N, Prezant TR, Chaltraw WE, et al. Mitochondrial gene mutation is a significant predisposing factor in aminoglycoside ototoxicity. Am J Otolaryngol 1997; 18:173178.

98 Braverman I, Jaber L, Levi H, et al. Audiovestibular findings in patients with deafness caused by a mitochondrial susceptibility mutation and precipitated by an inherited mutation or aminoglycosides. Arch Otolaryngol Head Neck Surg 1996; 122:10011004.

99 Sinnathuray AR, Raut V, Awa A, Magee A, Toner JG. A review of cochlear implantation in mitochondrial sensorineural hearing loss. Otol Neurotol 2003; 24:418-426.

100 Yamasoba T, Goto Y, Komaki H, Mimaki M, Sudo A, Suzuki M. Cochlear damage due to germanium-induced mitochondrial dysfunction in guinea pigs. Neurosci Lett 2006; 395:18-22.

101 McKenzie M, Liolitsa D, Hanna MG. Mitochondrial disease: mutations and mechanisms. Neurochem Res 2004; 29:589-600.

102 Ikeda K. Gene-based deafness research: ion transport and hearing. Tohoku J Exp Med 2004; 202:1-11.

103 Steel KP, Kros CJ. A genetic approach to understanding auditory function. Nat Genet 2001; 27:143-149. 